principles of the subject but it is certainly not suitable for the medical student. It is surprising that the author feels that the needs of the psychiatric nurse and the medical student could ever be satisfied by the same text book.

The book is characterized by a humane approach to the psychiatric patient which is so characteristic of the way of life in New Zealand, where Dr. Stallworthy lives and works. Equally characteristic is the manner in which it reflects the psychiatric attitudes of the home country, due regard being paid to the pathophysiology as well as the psychopathology of mental illness. It is written in simple language and in an easily comprehensible style but in spite of references to the latest neuroleptic and antidepressant drugs and to the abnormal chromosome pattern in mongols, there is a somewhat old-fashioned air about the volume which is not dispelled by lengthy accounts of deep insulin treatment, prolonged narcosis, hydrotherapy, the malarial treatment of general paresis and of the stringent precautions to be taken against suicide in depressed patients.

There is much that is good about this book but it is marred by a number of imprecise and loose statements; 'the rare temporal lobe epilepsy'; 'hallucinations occur only in the psychoses '; 'Korsakow's psychosis is an organic dementia . . . with an unusual tendency to confabulation'; 'the eunuch is impotent'. The chapter on epilepsy in particular is outmoded and the recommendation in the case of an attack of grand mal ' if he has teeth, try to open his mouth and insert some object' is downright dangerous.

There is a pressing need for a good text book of psychiatry for nurses and it is to be hoped that the project sponsored by the R.M.P.A. will fulfil this requirement. Until some such volume is available the psychiatric nurse in training might do worse than rely upon Dr. Stallworthy's manual.

\section{Nervous Inhibition: Proceedings of the Second Friday Harbor Symposium}

Editor: Ernest Florey. Pp. 475. Oxford, London, New York and Paris: Pergamon Press. 196r. £5.

When a group of international experts gather to discuss one small aspect of their field of work, it is unlikely they will have much to say of interest to the general reader. Moreover, their discussion is often couched in language which is barely intelligible to those outside the field. This cannot be said of the present symposium for, though the subject may not have general appeal, the contributions are lucid and to the point, and the illustrations are of unusually high quality.

The phenomenon of inhibition of an actual or potential activity in the nervous system has long been recognized, but the neural mechanisms by which this is achieved have equally long been obscure. Now, however, there can be no doubt that certain neurons are specifically concerned with inhibiting the activity of other,neurons. How this is achieved is to a large extent described in the various papers included here. There are, of course, many problems as yet unsolved. But within these pages we have a succinct description of the present position given by those best qualified, namely, people who are actively engaged in the study of the problem. There are also clear indications as to whef the future lies as, for example, in the paper on the inhibitory transmitters.

It cannot be expected that a book of this kind w have a wide sale, especially in view of its cost, but those interested in neurophysiology will find it a valuab book to have. The large number of references and the good index increases its value.

\section{Surgery of Trauma in the Tropics}

R. L. BAtTen. Pp. viii +234 , illustrated; Londorad Edward Arnold. r 961 . 35 s.

This short book is directed especially to those rê? sponsible for the treatment of trauma in smaller tropice्यु hospitals. Surgical practice in such circumstances is greatly influenced by poor communications, lack of special centres, uneducated population, scarcity of bloos for transfusion and the climate.

The book is short and includes a chapter on anæsthes? in its 234 pages. The discussion is therefore brief, bet the treatment advised is orthodox and full of commoge sense. There are some notable omissions, viz: surgical emphysema, acute renal failure and fat embolism.

The last 14 pages are devoted to instruments ang appliances. Perhaps this space would be better occupien by a description of the shock room, the method of examination of a patient with multiple injuries and discussion of the priority of treatment of the various injuries. The index is rather brief. The book is well illustrated and there is a short bibliography at the end of each chapter.

\section{Histology}

ARTHUR W. HAM, M.B., F.R.s.C., and Thomas LEESON, M.A., M.D., B.CH.(CANTAB.). Fourth edită̄id. Pp. xv + 942, illustrated. London: Pit Medical Publishing Co. 196r. £4 5 s.

Four editions in less than twelve years should sufficient recommendation for any standard work, and are especially remarkable in the relatively static field of histology. Ham's Histology owes its success to th functional presentation of cellular structure close related to physiological and pathological behaviour with this vital approach, anatomy, physiology, and bio chemistry become linked and interdependent. This new edition, with Dr. T. S. Leeson as a co-authos amplifies the modern methods of investigating cellular structure and function, and the breakdown of the individual cell into recognizable components with specialized activity is becoming a textbook realit. Advances in histology nowadays follow advances medical and other biological sciences, and our increasing knowledge of the importance of 5-hydroxytryptaming and of gastrin calls for more space devoted to intestina argentaffin cells, and to the non-insulin secreting cells of the islets of Langerhans. Histologists working with the light microscope realize that they must re-lear their subject with the electron microscope and add tional electron micrographs and descriptions of fing structure are particularly welcome. As a textbook pure and applied histology, this edition stands supremes it is beautifully produced and the price-so often 9 limiting factor in books originating from the New World-is most reasonable. 